\title{
Time to the Peak, Shape of the Curve and Combination of These Glucose Response Characteristics During Oral Glucose Tolerance Test as Indicators of Early Beta-cell Dysfunction in Obese Adolescents
}

\author{
(D) Lavinia La Grasta Sabolić1, (D) Marija Požgaj Šepec1, (1) Maja Cigrovski Berković2,3, (D) Gordana Stipančić1,4 \\ 1 University Hospital Center Sestre Milosrdnice, Department of Pediatric Endocrinology, Diabetes and Metabolism, Zagreb, Croatia \\ ${ }^{2}$ Clinical Hospital Dubrava, Department of Endocrinology, Diabetes, Metabolism and Clinical Pharmacology, Zagreb, Croatia \\ 3 University Osijek, Faculty of Medicine, Department of Pharmacology, Osijek, Croatia \\ 4University of Zagreb, School of Dental Medicine, Zagreb, Croatia
}

What is already known on this topic?

Oral glucose tolerance test (OGTT) is traditionally used to define glucose tolerance status based on 2-hour plasma glucose level. There is growing evidence that glucose curve characteristics, such as time of the glucose peak and shape of the glucose curve, may serve as indicators of beta-cell dysfunction.

\section{What this study adds?}

Late glucose peak, or a monophasic glucose curve during OGTT, are associated with impairment of beta-cell function in obese adolescents with normal glucose tolerance. Moreover, a combination of these glucose curve characteristics strongly predicts low oral disposition index.

\begin{abstract}
Objective: Characteristics of the glucose response during oral glucose tolerance test (OGTT) may reflect differences in insulin secretion and action. The aim was to examine whether timing of the glucose peak, shape of the glucose curve and their combination could be indicators of beta-cell dysfunction in obese/severely obese adolescents with normal glucose tolerance (NGT).

Methods: Data from 246 obese/severely obese adolescents who completed OGTT were reviewed. Out of 184 adolescents with NGT, 174 could be further classified into groups based on timing of the glucose peak (early/30 minutes vs late/ $\geq 60$ minutes) and shape of the glucose curve (monophasic vs biphasic). Groups were compared with respect to insulin sensitivity (whole body insulin sensitivity index - WBISI), early-phase insulin secretion (insulinogenic index - IGI) and beta-cell function relative to insulin sensitivity (oral disposition index - oDI).

Results: Late glucose peak $(p=0.004)$ and monophasic glucose curve $(p=0.001)$ were both associated with lower oDI after adjustment for age, sex, puberty stage and body mass index z-score. Among obese/severely obese adolescents with NGT, those with coexistent late glucose peak and monophasic glucose curve had lower oDI than those with early glucose peak and biphasic glucose curve $(p=0.002)$. Moreover, a combination of late glucose peak and monophasic glucose curve was the most powerful predictor of the lowest oDI quartile [odds ratio (OR): 11.68, 95\% confidence interval: 3.048-44.755, $\mathrm{p}<0.001$ ].

Conclusion: Late timing of the glucose peak, monophasic shape of the glucose curve and, in particular, a combination of those characteristics during OGTT may indicate early beta-cell dysfunction in obese/severely obese adolescents with NGT.
\end{abstract}

Keywords: Oral glucose tolerance test, beta-cell dysfunction, obese adolescents

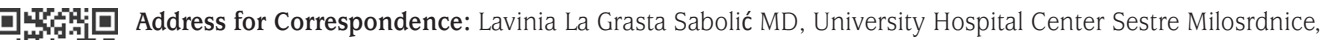
Department of Pediatric Endocrinology, Diabetes and Metabolism, Zagreb, Croatia Phone: + 38513787551 E-mail: lavinia.la.grasta.sabolic@gmail.com ORCID: orcid.org/0000-0001-9114-7961
Conflict of interest: None declared Received: 06.07.2020 Accepted: 29.09.2020

${ }^{\circ}$ Copyright 2021 by Turkish Pediatric Endocrinology and Diabetes Society

The Journal of Clinical Research in Pediatric Endocrinology published by Galenos Publishing House. 


\section{Introduction}

Oral glucose tolerance test (OGTT) has been used traditionally to diagnose dysglycemia, according to fasting and 2-hour post-load glucose thresholds $(1,2)$. However, even obese individuals with initially normal glucose tolerance (NGT) can eventually develop prediabetes and progress to type 2 diabetes $(3,4,5)$. Impaired insulin secretion relative to insulin sensitivity, reflecting an early defect in betacell function, presents a key pathophysiological feature in those with the highest risk for disease progression (5). Identifying the predictors of beta-cell dysfunction in obese normoglycemic adolescents might be important for timely prevention of diabetes in youth $(5,6)$. In recent years it has been investigated whether some features of the glucose response during OGTT, including time of the glucose peak and shape of the glucose curve, could be used as predictors of insulin secretion relative to insulin sensitivity.

Time of the glucose peak was found to be a reliably reproducible variable of the OGTT (7). It's role in prediction of beta-cell dysfunction has been studied in adult populations $(8,9,10)$. Delayed timing of post-load glucose peak $>30$ minutes was associated with declining beta-cell function, worsening glucose tolerance over time (8) and a greater likelihood of prediabetes and diabetes $(9,10)$. To our knowledge, association of glucose peak time and beta-cell function in youth has not been thoroughly investigated. So far, time of the glucose peak has been explored as potential predictor of beta-cell function and prediabetes risk in post-pubertal overweight/obese adolescent girls of diverse ethnicity (11) and recently in overweight/obese white and black adolescents (12).

A monophasic glucose curve shape has already been investigated as an early marker of beta-cell dysfunction and a risk predictor for type 2 diabetes in adults $(13,14,15)$, pregnant women (16) and adolescents $(17,18,19)$. In addition, a monophasic glucose curve predicted the risk for progression to type 1 diabetes among autoantibody-positive relatives of people with type 1 diabetes. Moreover, the risk in the monophasic group was increased with delayed timing of the glucose peak (20).

As time of the glucose peak and shape of the glucose curve reflect differences in insulin secretion and action, they deserve further investigation and validation in different populations, including obese youth. The joint ability of these two features of the OGTT to detect impaired beta-cell function is not sufficiently explored.

Therefore the aims of the present study were: 1) to investigate time of the glucose peak and shape of the glucose curve as independent predictors of beta-cell dysfunction and; 2) to explore their joint ability to detect impaired beta-cell function in obese/severely obese adolescents.

\section{Methods}

\section{Participants}

This retrospective analysis included data from 246 adolescents aged 10-18 years, referred for obesity to Department of Pediatric Endocrinology at the University Hospital Center Sestre milosrdnice, who subsequently completed 2-hour OGTT from January 2016 to March 2018. None of them was previously treated for obesity. Subjects taking any medication or having any systemic or endocrine disease, as well as those fulfilling the OGTT criteria for prediabetes or diabetes $(1,2)$ were excluded $(n=62)$. Out of 184 adolescents with NGT, 174 could be classified based on both time of the glucose peak and shape of the glucose curve, and their data were further analysed.

The study protocol was approved by the Ethics Committee of the University Hospital Center Sestre milosrdnice (approval number: 251-29-11-20-01-3). The requirement for informed consent was waived due to the retrospective nature of the study.

\section{Anthropometric Measurements}

Body weight was measured using a digital weighting scale to the nearest $0.1 \mathrm{~kg}$, with subjects wearing only underwear. Standing height was measured with a Harpenden stadiometer to the nearest $0.1 \mathrm{~cm}$. Body mass index (BMI) was calculated by dividing weight (kg) by height in metres squared $\left(\mathrm{m}^{2}\right)$. Obesity was defined as BMI $\geq 95^{\text {th }}$ percentile for age and sex (21). Subjects were further classified as either obese if having a BMI $\geq 95^{\text {th }}$ percentile and $<120 \%$ of the $95^{\text {th }}$ percentile for age and sex or severely obese if having a BMI $\geq 120 \%$ of the $95^{\text {th }}$ percentile for age and sex or an absolute BMI $\geq 35 \mathrm{~kg} / \mathrm{m}^{2}$ (22), whichever was lower. The BMI z-score was calculated using US reference values (21). The pubertal stage was assessed using Tanner criteria (23).

\section{Oral Glucose Tolerance Testing}

After 10-12 hour overnight fast, a standard OGTT was performed with ingestion of the glucose load, $1.75 \mathrm{~g} / \mathrm{kg}$ body weight, up to $75 \mathrm{~g}$ of glucose. Venous blood samples for measurement of plasma glucose and serum insulin were obtained at 0, 30, 60, 90 and 120 minutes. NGT was defined as fasting glucose $<5.6 \mathrm{mmol} / \mathrm{L}$ and 2 hour glucose $<7.8$ $\mathrm{mmol} / \mathrm{L}(1)$. 
Classification of the Glucose Response-time of the Glucose Peak, Shape of the Glucose Curve

With respect to timing of the first glucose peak during OGTT, glucose response was dichotomized as maximal glucose occuring at 30 or $\geq 60$ minutes (excluding 120 minutes due to inapplicability for the shape classification stated below). The glucose peak was considered either early (at 30 minutes) or late ( $\geq 60$ minutes).

Shape of the glucose curve was classified as monophasic or biphasic (24). A monophasic curve was characterised by an increase of glucose to a maximum between 30-90 minutes, followed by a decrease until 120 minutes. The curve was classified as biphasic if glucose peaked at 30 or 60 minutes, followed by a nadir and a second peak by 120 minutes. The upward or downward change in plasma glucose between the time points was defined as glucose difference of $\geq 0.2$ $\mathrm{mmol} / \mathrm{L}$ to minimize fluctuations in glucose concentrations, which may be caused by the method of glucose analysis, rather than physiological reasons. Ten subjects with NGT who could not be classified according to the aforementioned criteria were excluded from further analysis (inability to determine glucose peak time $(n=3)$, curve shape $(n=3)$ or peak time and curve shape $(n=2)$, incessant increase $(n=1)$ and paradoxical glucose response $(n=1)$.

\section{Calculations Derived from OGTT}

Insulin sensitivity was assessed using the Matsuda index, an established measure of whole body insulin sensitivity index (WBISI), which has been validated against the euglycaemichyperinsulinaemic clamp, and calculated as: WBISI $=10$ 000/V [(fasting glucose $(\mathrm{mmol} / \mathrm{L}) \times 18.02 \times$ fasting insulin $(\mathrm{mIU} / \mathrm{L})) \times($ mean glucose $(\mathrm{mmol} / \mathrm{L}) \times 18.02 \times$ mean insulin $(\mathrm{mIU} / \mathrm{L}))](25)$.

Early-phase insulin secretion was assessed using the insulinogenic index (IGI), which was calculated as the ratio of the incremental change of plasma insulin (mIU/L) to that of plasma glucose $(\mathrm{mmol} / \mathrm{L})$ during the first 30 minutes after glucose ingestion, as: IGI $=\Delta$ Insulin $_{30} / \Delta$ Glucose $_{30} \times 18.02$ (26).

In addition, in order to assess beta-cell function relative to insulin sensitivity, oral disposition index (oDI) was calculated as the product of WBISI and IGI. As a surrogate estimate of beta-cell function relative to insulin sensitivity, oDI can be applied to obese adolescents in studies where the applicability of clamp studies is limited due to feasibility, cost and labor intensiveness (27).

\section{Protocol}

Subjects were initially grouped based on whether time of the glucose peak occured early (at 30 minutes, $\mathrm{P}_{30}$ ) or late
( $\geq 60$ minutes, $P \geq_{60}$ ). Those two groups were compared with respect to WBISI, IGI and oDI.

Participants were subsequently grouped according to shape of the glucose curve as either monophasic (M) or biphasic (B) and compared with respect to WBISI, IGI and oDI.

Subjects were finally stratified into four groups, those with: (1) early glucose peak and monophasic curve shape $\left(\mathrm{P}_{30} \mathrm{M}\right)$; (2) early glucose peak and biphasic curve shape $\left(\mathrm{P}_{30} \mathrm{~B}\right)$; (3) late glucose peak and biphasic curve shape $\left(\mathrm{P} \geq_{60} \mathrm{~B}\right)$; (4) late glucose peak and monophasic curve shape $\left(\mathrm{P} \geq_{60} \mathrm{M}\right)$. Groups were compared with respect to WBISI, IGI and oDI.

\section{Analytical Methods}

Plasma glucose concentration was determined by the hexokinase method on the Abbott Architect c 8000 chemistry analyzer (Abbott Diagnostics, USA). Serum insulin was assessed by the electrochemiluminescence immunoassay on the Cobas E601 analyzer (Roche Diagnostics, Germany).

\section{Statistical Analysis}

Statistical analysis was performed using Statistical Package for the Social Sciences 25.0.0.1. (IBM Inc., Armonk, NY, USA).

Descriptive statistics was used to describe the basic features of the sample in the study, using relative frequencies for categorical variables, and mean and standard deviation for continuous variables. Since some variables deviated from normal distribution, non-parametric descriptive parameters, median and interquartile range were also calculated. Normality of distribution was tested using Shapiro-Wilk test. To test statistical significance of differences between obese and severely obese group of participants, independent samples t-test and chi-square were calculated. ANOVA and ANCOVA adjusted for age, sex, Tanner stage and BMI SDS were used to determine the association of glucose peak timing, glucose curve shape and combined glucose curve features with insulin sensitivity, early-phase insulin secretion and beta-cell function relative to insulin sensitivity. Logistic regression was used to explore the relationship between predictor variables and the lowest oDI quartile. $\mathrm{P}$ values $<0.05$ were considered statistically significant.

\section{Results}

\section{Demographic Characteristics of Study Participants}

There were no statistically significant differences between the groups of obese $(n=76)$ and severely obese $(n=98)$ adolescents with respect to age $(p=0.127)$, sex $(p=0.357)$ and puberty stage $(p=0.929)$ (Table 1$)$. 
OGTT-derived Indices of Insulin Sensitivity, Secretion and Betacell Function in Obese vs Severely Obese Adolescents

The group of severely obese adolescents had significantly lower WBISI $(p=0.002)$ and oDI $(p=0.019)$ than the obese group. At the same time, there was no difference in IGI $(p=0.420)$ between the groups (Table 1$)$.

\section{Prevalence of Glucose Curve Characteristics with Respect to Time of the Glucose Peak and Shape of the Glucose Curve}

Early glucose peak and monophasic glucose curve were the prevalent morphological features identified, irrespective of the degree of obesity, while the most common curve characteristics with combined features were biphasic curve with early glucose peak and monophasic curve with late glucose peak (Table 2).

Among the participants, $57.5 \%$ (100/174) had a glucose peak at 30 minutes and $42.5 \%(74 / 174)$ at $\geq 60$ minutes. Glucose curve was monophasic in $55.7 \%$ (97/174) and biphasic in $44.3 \%(77 / 174)$ of subjects. A biphasic curve with glucose peak at 30 minutes was identified in $36.2 \%$ (63/174), a monophasic curve with glucose peak at $\geq 60$ minutes in $34.5 \%(60 / 174)$, a monophasic curve with glucose peak at 30 minutes in $21.3 \%$ (37/174), and a biphasic curve with glucose peak at $\geq 60$ minutes in $8 \%(14 / 174)$.

In adolescents with glucose peak at 30 minutes, $63 \%$ (63/100) had biphasic glucose curve. In individuals with glucose peak at $\geq 60$ minutes, $81.1 \%$ (60/74) had monophasic glucose curve.
In subjects with biphasic curve, $81.8 \%(63 / 77)$ had glucose peak at 30 minutes, while in those with monophasic curve, $61.9 \%$ (60/97) had glucose peak at $\geq 60$ minutes.

More frequent association of early glucose peak and biphasic curve, as well as association of late glucose peak and monophasic curve was observed in both obese and severely obese adolescents (Table 2).

\section{Relationship of Glucose Curve Characteristics and OGTT-derived Indices}

\section{Time of the Glucose Peak}

After adjustment for age, sex, puberty stage and BMI z-score, glucose peak at $\geq 60$ minutes was associated with lower oDI $(p=0.004)$ (Figure 1A, Table 3). There was no statistically significant difference in WBISI between the groups with glucose peak at 30 and $\geq 60$ minutes $(p=0.302)$, while a trend towards lower IGI with glucose peak at $\geq 60$ minutes did not reach statistical significance $(p=0.057)$ (Table 3 ).

\section{Shape of the Glucose Curve}

No difference between the groups with monophasic and biphasic glucose curve was observed with respect to WBISI $(\mathrm{p}=0.784)$ after adjustment for age, sex, puberty stage and BMI z-score (Table 3). However, adolescents with monophasic curve had lower IGI $(p<0.001)$ and oDI $(p=0.001)$ (Figure 1B, Table 3).

Table 1. Demographic characteristics of study participants and oral glucose tolerance test-derived indices of insulin sensitivity, secretion and beta-cell function

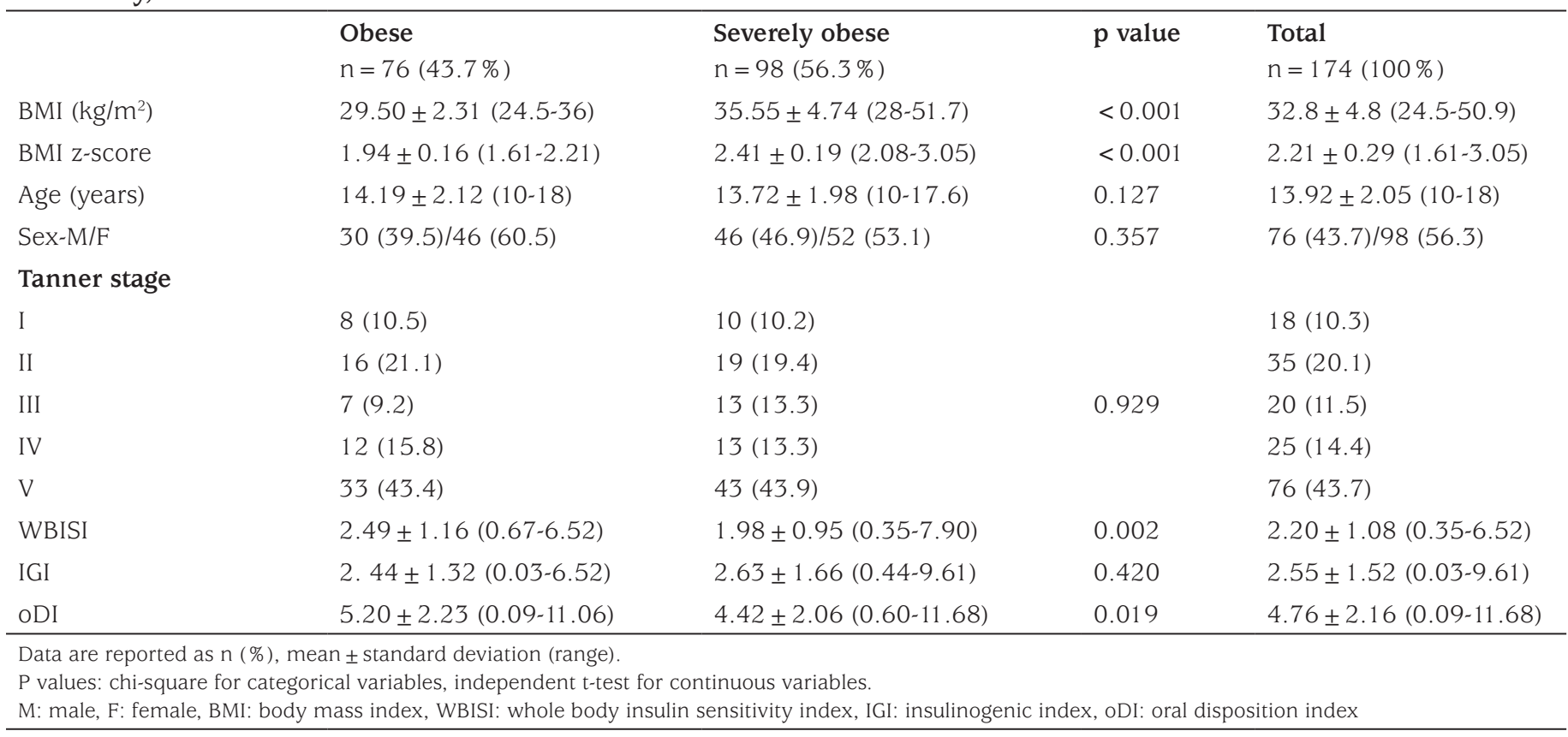


Table 2. Prevalence of glucose curve characteristics in obese vs severely obese adolescents

\begin{tabular}{llll}
\hline $\begin{array}{l}\text { Glucose curve } \\
\text { characteristics }\end{array}$ & $\begin{array}{l}\text { Obese } \\
\mathbf{n}=76\end{array}$ & $\begin{array}{l}\text { Severely obese } \\
\mathbf{n}=98\end{array}$ & $\mathrm{p}$ value* \\
$\mathbf{P}_{30}$ & $46(60.5)$ & $54(55.1)$ & \\
$\mathbf{P}_{60}$ & $30(39.5)$ & $44(44.9)$ & 0.537 \\
$\mathbf{M}$ & $41(53.9)$ & $56(57.1)$ & \\
$\mathbf{B}$ & $35(46.1)$ & $42(42.9)$ & 0.759 \\
$\mathbf{P}_{30} \mathbf{M}$ & $18(23.7)$ & $19(19.4)$ & \\
$\mathbf{P}_{30} \mathbf{B}$ & $28(36.8)$ & $35(35.7)$ & \\
$\mathbf{P} \geq_{60} \mathrm{~B}$ & $7(9.2)$ & $7(7.1)$ & 0.727 \\
$\mathrm{P} \geq_{60} \mathbf{M}$ & $23(30.3)$ & $37(37.8)$ & \\
\hline
\end{tabular}

Data are reported as $\mathrm{n}(\%) ; \mathrm{P}_{30}$ : glucose peak at 30 minutes, $\mathrm{P} \geq_{60}$ : glucose peak at $\geq 60$ minutes, M: monophasic glucose curve, B: biphasic glucose curve

* Significance of differences between obese and severely obese adolescents in each glucose curve characteristics frequency: chi-square statistics (Fisher's exact test for $2 \times 2$ tables)

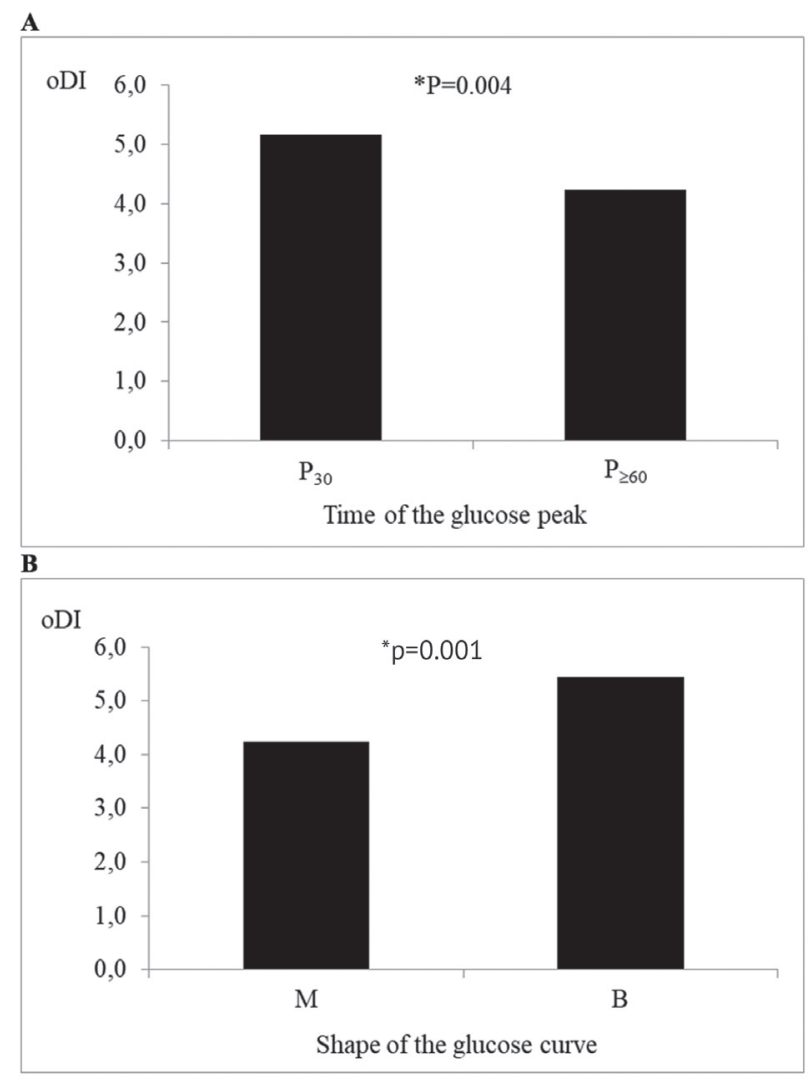

Figure 1. Comparison of average oral disposition index in groups with: (A) early vs late glucose peak; (B) monophasic vs biphasic glucose curve

* After adjustment for age, sex, puberty stage and body mass index z-score.

oDI: oral disposition index, $P_{30}:$ glucose peak at 30 mintues, $P \geq_{60}$ : glucose peak at $\geq 60$ minutes, $M$ : monophasic glucose curve, B: biphasic glucose curve

\section{Time of the Glucose Peak and Shape of the Glucose Curve as Combined Glucose Curve Characteristics}

Among four groups with combined glucose curve characteristics $\left(\mathrm{P}_{30} \mathrm{M}, \quad \mathrm{P}_{30} \mathrm{~B}, \quad \mathrm{P} \geq_{60} \mathrm{~B}\right.$ and $\left.\mathrm{P} \geq_{60} \mathrm{M}\right)$, after adjustment for age, sex, puberty stage and BMI z-score, significant differences were found for IGI $(p=0.001)$ and oDI $(p=0.004) . P_{30} M$ group had lower IGI than $P_{30} B$ group, while $\mathrm{P} \geq_{60} \mathrm{M}$ group had both lower IGI and lower oDI than $\mathrm{P}_{30} \mathrm{~B}$ group (Figure 2).

\section{Time of the Glucose Peak and Shape of the Glucose Curve as Predictors of Low ODI}

Among adolescents with oDI in the first (lowest) quartile, the proportion of those having glucose peak at $\geq 60$ minutes was significantly higher than among adolescents with oDI in the third or fourth quartile, whose predominant glucose peak time was 30 minutes $\left(\chi^{2}=10.281, d f=3, p=0.016\right)$ (Figure 3A).

With regard to the shape of the glucose curve, proportion of subjects with monophasic glucose curve was significantly higher among adolescents with oDI in the first quartile, while participants with biphasic glucose curve were more prevalent among adolescents with oDI in the third or fourth quartile $\left(\chi^{2}=17.135, \mathrm{df}=3, \mathrm{p}=0.001\right)$ (Figure 3B).

According to logistic regression, when age, sex, puberty stage and BMI z-score were included in the model, probability to have oDI in the lowest quartile was almost three times higher in adolescents with late (vs early) glucose peak [odds ratio (OR): $2.96,95 \%$ confidence interval $(\mathrm{CI}): 1.3339$ 6.526, $p=0.007$, almost five times higher in subjects with monophasic (vs biphasic) glucose curve (OR: $4.91,95 \% \mathrm{CI}$ : 1.856-12.977, $\mathrm{p}=0.001$ ), and almost twelve times higher in participants with combination of late glucose peak and monophasic glucose curve (vs combination of early glucose peak and biphasic glucose curve) (OR: 11.68 , $95 \%$ CI: 3.04844.755, p < 0.001).

\section{Discussion}

This study indicates that morphological characteristics of the glucose response curve during OGTT, including time of the glucose peak, shape of the glucose curve and combination of these features, may be informative of impaired beta-cell function in obese/severely obese youth with NGT.

There was no statistically significant difference in the prevalence of glucose curve characteristics, including time of the glucose peak, shape of the glucose curve or both features combined, between otherwise demographically comparable groups of obese/severely obese adolescents. 


\begin{tabular}{|c|c|c|c|c|c|c|}
\hline \multirow[t]{2}{*}{ OGTT-derived indices } & \multicolumn{3}{|c|}{ Time of the glucose peak } & \multicolumn{3}{|c|}{ Shape of the glucose curve } \\
\hline & $P_{30}$ & $\mathrm{P} \geq_{60}$ & * p value & B & $\mathrm{M}$ & ${ }^{*} \mathrm{p}$ value \\
\hline WBISI & $\begin{array}{l}2.30 \pm 1.13 \\
(0.66-7.9)\end{array}$ & $\begin{array}{l}2.08 \pm 1.00 \\
(0.35-4.94)\end{array}$ & 0.302 & $\begin{array}{l}2.21 \pm 1.06 \\
(\mathbf{0 . 6 6 - 5 . 1 3 )}\end{array}$ & $\begin{array}{l}2.20 \pm 1.10 \\
(\mathbf{0 . 3 5 - 7 . 9 )}\end{array}$ & 0.784 \\
\hline IGI & $\begin{array}{l}2.76 \pm 1.62 \\
(0.62-9.61)\end{array}$ & $\begin{array}{l}2.27 \pm 1.32 \\
(0.44-7.13)\end{array}$ & 0.057 & $\begin{array}{l}3.04 \pm 1.72 \\
(\mathbf{0 . 7 7 - 9 . 6 1 )}\end{array}$ & $\begin{array}{l}2.16 \pm 1.21 \\
(0.44-7.13)\end{array}$ & $<0.001$ \\
\hline oDI & $\begin{array}{l}5.23 \pm 2.16 \\
(\mathbf{1 . 2 3 - 1 1 . 6 8 )}\end{array}$ & $\begin{array}{l}4.15 \pm 2.02 \\
(\mathbf{0 . 6 8 - 1 0 . 5 7 )}\end{array}$ & 0.004 & $\begin{array}{l}5.44 \pm 2.07 \\
(\mathbf{1 . 6 4 - 1 1 . 3 )}\end{array}$ & $\begin{array}{l}4.25 \pm 2.10 \\
\mathbf{( 0 . 6 8 - 1 1 . 6 8 )}\end{array}$ & 0.001 \\
\hline
\end{tabular}

Data are reported as mean \pm standard deviation (range); WBISI: whole body insulin sensitivity index, IGI: insulinogenic index, oDI: oral disposition index, $\mathrm{P}_{30}$ : glucose peak at 30 mintues, $\mathrm{P} \geq_{60}$ : glucose peak at $\geq 60$ minutes, M: monophasic glucose curve, B: biphasic glucose curve, OGTT: oral glucose tolerance test *After adjustment for age, sex, puberty stage and body mass index z-score

Through the literature search, we found no similar data comparing the prevalence of glucose curve characteristics in subjects with different obesity classes.

As expected, severely obese adolescents had lower WBISI, reflecting lower insulin sensitivity $(28,29)$. Insulin secretion expressed as IGI did not differ significantly between the groups. However, beta-cell function was worse in severely obese adolescents, which is consistent with previous findings $(30,31)$.

Prevalent features of the glucose response in our sample of obese/severely obese adolescents with NGT were early glucose peak and monophasic glucose curve. According to studies published to date, early glucose peak was detected in a minority of obese postpubertal adolescent girls with NGT or prediabetes (34/88) (11) and in approximately half of obese black and white adolescents with NGT or impaired glucose tolerance (IGT) (142/278) (12). A higher proportion of subjects with early glucose peak in the current study (100/174) is probably due to normotolerant glucose status of the included adolescents and is in agreement with crosssectional analyses that have linked later time of the glucose peak with impaired glucose tolerance and type 2 diabetes $(7,32)$. With regard to the prevalence of the monophasic glucose curve, our findings are in line with formerly published data for obese adolescents with NGT (33). The prevalence of combined glucose curve characteristics involving time of the glucose peak and shape of the glucose curve has not been thoroughly investigated. According to our results, $71 \%$ of participants had either early glucose peak with biphasic curve or late glucose peak with monophasic curve. In the study of Chung et al (9), normotolerant or prediabetic adults with glucose peak $>30$ minutes more often had monophasic glucose curve $(78 \%)$, while those with glucose peak at 30 minutes had an equal chance of having either biphasic or monophasic curve ( $54 \%$ vs $45 \%$ ). In the present study, adolescents with late glucose peak more frequently had monophasic glucose curve too $(81 \%)$, but in subjects with early glucose peak a higher prevalence of biphasic curve was detected $(63 \%)$. As younger persons are more likely to be characterized by a biphasic glucose response $(19,24)$, our results suggesting a stronger association of early glucose peak and biphasic glucose curve may be atributed to younger age and normotolerant glucose status of the included subjects. In non-diabetic Latino adolescents, the biphasic group exhibited a higher percentage of "early responders" compared with the monophasic group (57\% vs $32 \%$ ) (18), and this trend was even more pronounced in our sample ( $82 \%$ vs $38 \%$ ).

The time point after an oral glucose load at which the peak glucose concentration occurs has recently been shown to represent a reliably reproducible parameter of the OGTT, with $76 \%$ agreement on triplicate testing performed at three different days (7). In addition, time to glucose peak has already emerged as a potential predictor of betacell function in adults, while only scarce data related to adolesents currently exist. In adults, cross-sectional studies have linked a late glucose peak during OGTT with beta-cell dysfunction, impaired glucose tolerance and type 2 diabetes $(7,9,10)$. A longitudinal study comprising 532 women in the first year postpartum, revealed that both a shift of the glucose peak to a later time point and a consistently delayed glucose peak were associated with declining betacell function and worsening of glucose tolerance status over a nine month period (8). In adults with newly diagnosed type 2 diabetes, time to glucose peak during OGTT was assessed before and after four weeks of intensive insulin therapy; a resultant improvement of beta-cell function was associated with a shift of the glucose peak to an earlier time point (7). Regarding the adolescent population, 54 overweight/obese postpubertal girls with late glucose peak had lower insulin sensitivity index $(p=0.004)$ and oDI $(p<0.001)$ than 34 girls with earlier glucose peak (11). Nolfe et al (33) also supported the concept that the more quickly the plasma glucose concentration returned to or below the 
$\mathbf{A}$

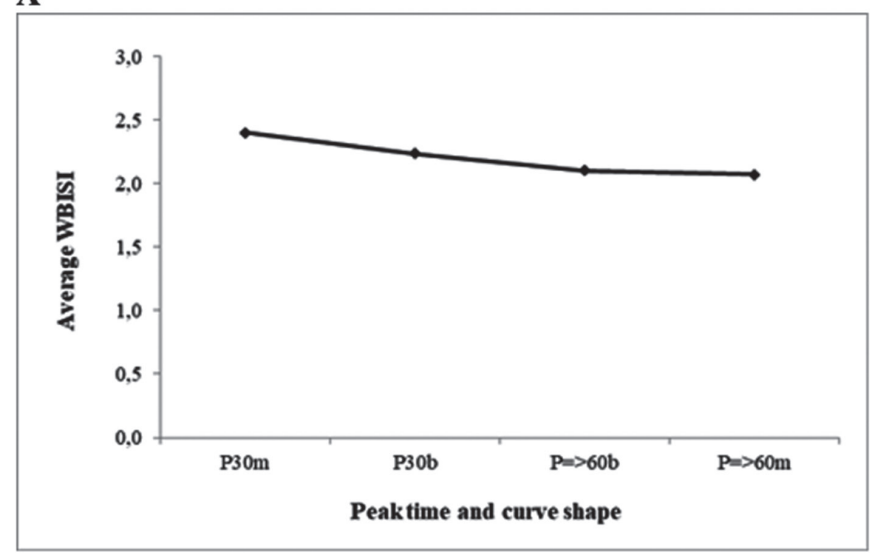

B

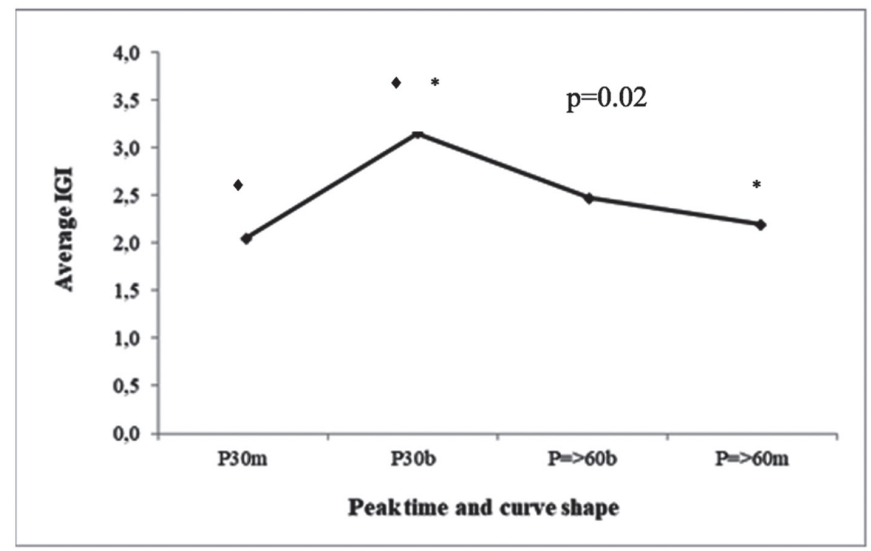

C

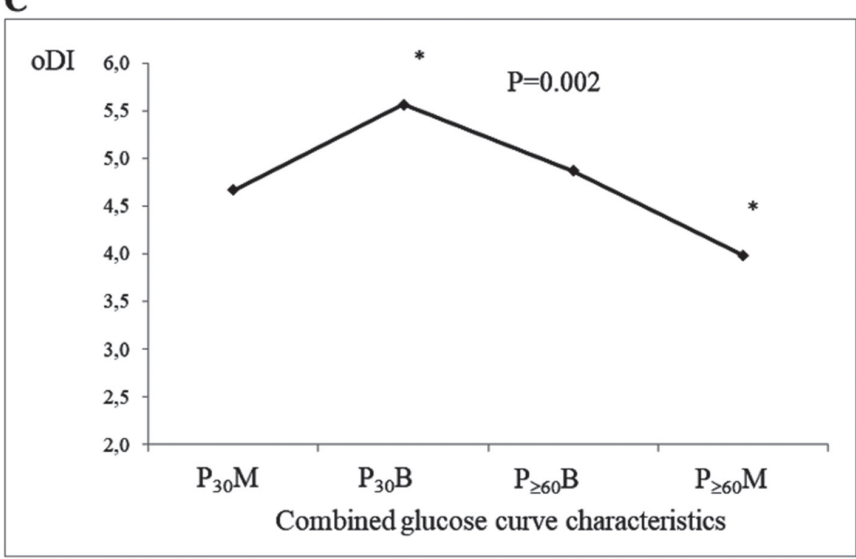

Figure 2. Comparison of average whole body insulin sensitivity index (A), insulinogenic index (B) and oral disposition index (C) in groups with combined glucose curve characteristics

-*Statistically significant difference after adjustment for age, sex, puberty stage and body mass index z-score.

WBISI: whole body insulin sensitivity index, IGI: insulinogenic index, oDI: oral disposition index, $P_{30} M$ : glucose peak at 30 mintues and monophasic glucose curve, $P_{30} B$ : glucose peak at 30 minutes and biphasic glucose curve, $P \geq_{60} B$ : glucose peak at $\geq 60$ minutes and biphasic glucose curve, $P \geq_{60} M$ glucose peak at $\geq 60$ minutes and monophasic glucose curve
A

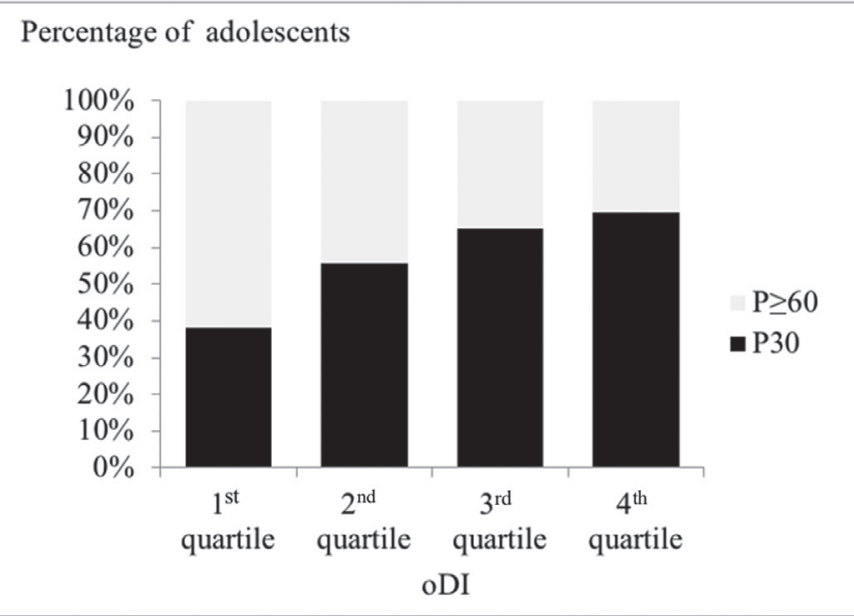

B

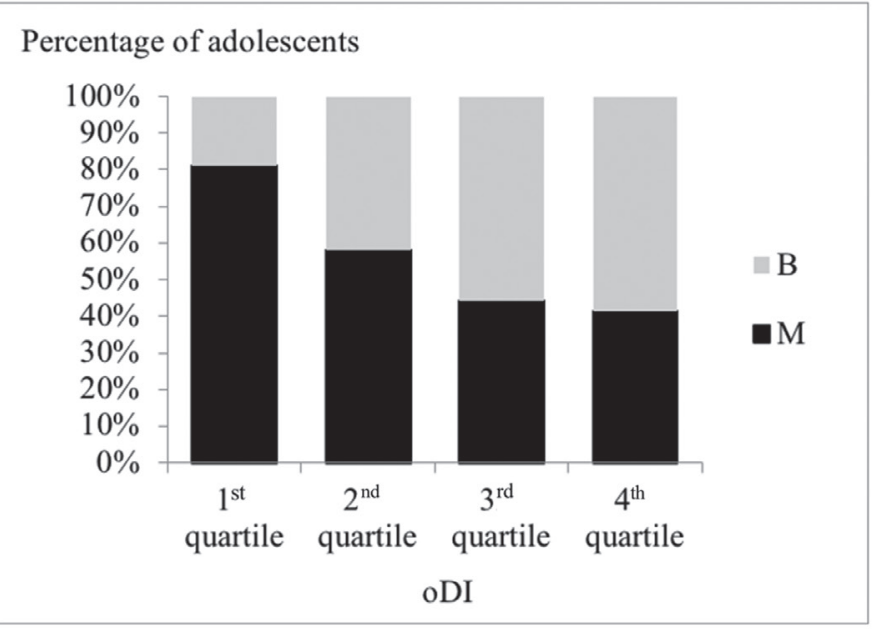

Figure 3. Percentage of adolescents with: (A) early vs late glucose peak in each quartile of oral disposition index (oDI); (B) biphasic vs monophasic glucose curve in each quartile of oDI

oDI: oral disposition index

fasting glucose level following glucose ingestion, which was associated with earlier glucose peak, the lower was the risk for future diabetes. In the present study, participants with late glucose peak had lower oDI than subjects with early glucose peak $(p=0.002)$. Our findings are in agreement with cross-sectional analyses linking delayed glucose peak with early defect in beta-cell function $(8,9,10,11,12)$.

The significance of the glucose curve shape was first established in adults. Beta-cell function, adjusted for insulin resistance, was found to be significantly lower in non-diabetic individuals with monophasic glucose curve. Moreover, a monophasic glucose response was more prevalent among subjects with IGT than in individuals with NGT (13). Another study linked monophasic glucose curve shape with increased risk for type 2 diabetes. Over a 7-8 years follow-up, the conversion rate to type 2 diabetes in 
prediabetic adults with monophasic glucose curve was twice that of subjects with a biphasic glucose response (14). Although questions regarding the curve shape stability were initially raised, recent data suggest that it is high (34). In the European Group for the Study of Insulin ResistanceRelationship between Insulin Sensitivity and Cardiovascular Disease cohort, $70 \%$ of participants presented with monophasic OGTT-glucose curve shape both at baseline and three years later (15). Besides that, persistence over time of a monophasic shape and switch from biphasic to monophasic shape was associated with increased risk of impaired glucose metabolism (15). Cross-sectional studies in adolescents $(17,18)$, including clamp studies in obese youth of both sexes and all pubertal stages (19), found a monophasic glucose curve shape to be associated with significantly worse beta-cell function relative to insulin sensitivity. In our study, after adjustment for age, sex, puberty stage and BMI z-score, subjects with monophasic glucose response had lower oDI $(p=0.001)$ reflecting poorer $\beta$-cell function, which is in accordance with findings of other studies performed in youth $(17,18,19)$.

The glucose curve shapes observed within a 2-hour window during OGTT are partially influenced by the time of the first glucose peak. Subjects with early peak are more likely to have biphasic, while those with late peak more often have monophasic curve shape. Cree-Green et al (11) found that peak glucose time was more predictive of $\beta$-cell function than shape of the glucose curve. Similar findings were published in an adult cohort with increased risk for type 2 diabetes (9).

To our knowledge, significance of combined glucose curve features in the detection of beta-cell dysfunction have not been investigated. Thus, we further categorised subjects according to the combination of both features, time of the glucose peak and shape of the glucose curve. Adolescents with late glucose peak and monophasic curve shape had lower oDI than those with early peak and biphasic curve shape $(p=0.002)$. Moreover, a combination of late glucose peak and monophasic glucose curve proved to be the strongest predictor of poor beta-cell function, as reflected by the highest risk of oDI in the lowest quartile (OR: 11.68, $95 \%$ CI: 3.048-44.755, p<0.001). We found no data in the literature highlighting the fact that glucose normotolerant adolescents with the combination of late glucose peak and monophasic glucose response during OGTT are at increased risk for poor beta-cell function.

\section{Study Limitations}

In the current study, time of the glucose peak and shape of the glucose curve were determined by a single OGTT.
Although recent studies in adults suggest glucose response pattern reproducibility and persistance over time $(7,15)$, youth-specific investigation of glucose curve characteristics are needed. In addition, our classification of glucose curve response was based on 2-hour OGTT with standard 30-minutes sampling intervals. By using more frequent sampling intervals, it could be possible to capture more details and probably provide better information on beta-cell function. Another drawback of this study was the inability to assign all the adolescents with NGT to either early/late glucose peak or monophasic/biphasic glucose response group, due to the criteria needed for glucose response classification. However, the number of unclassified subjects was small $(n=10,0.05 \%)$. Finally, factors which could influence the gastric emptying or differences in pre-test carbohydrate loading were not assessed in the present study.

Prospective longitudinal studies in obese adolescents are needed to confirm the predictive value of glucose response curve morphology with respect to deterioration of betacell function and progression from NGT to prediabetes or type 2 diabetes. In addition, lifestyle interventions in obese adolescents with poor beta-cell function should be investigated to understand if these interventions could shift the glucose peak to an earlier time point and/or glucose curve shape from monophasic to biphasic.

\section{Conclusion}

Early identification of subjects at high risk for type 2 diabetes among obese adolescents requires studies that focus on the initial stages of the disease, before the onset of any alterations in glucose tolerance. The present study confirms that obese adolescents with late glucose peak, as well as those with monophasic glucose response during OGTT, although normoglycemic, have reduced beta-cell function relative to insulin sensitivity. The risk of impaired beta-cell function is even more pronounced in obese youth with the aforementioned glucose curve features combined, making them a target population for intensive lifestyle intervention.

\section{Acknowledgments}

The authors thank the adolescents engaged in this study and their parents for cooperation and willingness, as well as the nursing staff of the Department of Pediatric Endocrinology, Diabetes and Metabolism for their outstanding care for participants.

\section{Ethics}

Ethics Committee Approval: The study protocol was approved by the Ethics Committee of the University Hospital 
Center Sestre Milosrdnice (approval number: 251-29-11-2001-3).

Informed Consent: The requirement for informed consent was waived due to the retrospective nature of the study.

Peer-review: Externally peer-reviewed.

\section{Authorship Contributions}

Surgical and Medical Practices: Marija Požgaj Šepec, Concept: Maja Cigrovski Berković, Gordana Stipančić, Design: Lavinia La Grasta Sabolić, Maja Cigrovski Berković, Gordana Stipančić, Data Collection or Processing: Lavinia La Grasta Sabolić, Analysis or Interpretation: Lavinia La Grasta Sabolić, Maja Cigrovski Berković, Gordana Stipančić, Literature Search: Marija Požgaj Šepec, Writing: Lavinia La Grasta Sabolić, Marija Požgaj Šepec, Maja Cigrovski Berković, Gordana Stipančić.

Financial Disclosure: The authors declared that this study received no financial support.

\section{References}

1. American Diabetes Association. Classification and diagnosis of diabetes. Diabetes Care 2017;40(Suppl 1):11-24.

2. World Health Organization. Definition and diagnosis of diabetes mellitus and intermediate hyperglycemia: report of a WHO/IDF consultation. Geneva, World Health Organization, 2006;1-50.

3. Ferrannini E, Nannipieri M, Williams K, Gonzales C, Haffner SM, Stern MP. Mode of onset of type 2 diabetes from normal or impaired glucose tolerance. Diabetes 2004;53:160-165.

4. Bacha F, Lee S, Gungor N, Arslanian SA. From pre-diabetes to type 2 diabetes in obese youth: pathophysiological characteristics along the spectrum of glucose dysregulation. Diabetes Care 2010;33:2225-2231. Epub 2010 Jun 30

5. D'Adamo E, Caprio S. Type 2 diabetes in youth: epidemiology and pathophysiology. Diabetes Care 2011;34(Suppl 2):161-165

6. Cali AM, Man CD, Cobelli C, Dziura J, Seyal A, Shaw M, Allen K, Chen S, Caprio S. Primary defects in beta-cell function further exacerbated by worsening of insulin resistance mark the development of impaired glucose tolerance in obese adolescents. Diabetes Care 2009;32:456461. Epub 2008 Dec 23

7. Kramer CK, Vuksan V, Choi H, Zinman B, Retnakaran R. Emerging parameters of the insulin and glucose response on the oral glucose tolerance test: reproducibility and implications for glucose homeostasis in individuals with and without diabetes. Diabetes Res Clin Pract 2014;105:88-95. Epub 2014 Apr 28

8. Kramer CK, Ye C, Hanley AJ, Connelly PW, Sermer M, Zinman B, Retnakaran R. Delayed timing of post-challenge peak blood glucose predicts declining beta cell function and worsening glucose tolerance over time: insight from the first year postpartum. Diabetologia 2015;58:1354-1362. Epub 2015 Mar 12

9. Chung ST, Ha J, Onuzuruike AU, Kasturi K, Galvan-De La Cruz M, Bingham BA, Baker RL, Utumatwishima JN, Mabundo LS, Ricks M, Sherman AS, Sumner AE. Time to glucose peak during an oral glucose tolerance test identifies prediabetes risk. Clin Endocrinol (Oxf) 2017;87:484-491. Epub 2017 Aug 6
10. Lin YC, Chen HS. Longer time to peak glucose during the oral glucose tolerance test increases cardiovascular risk score and diabetes prevalence. PLoS One 2017;12:e0189047.

11. Cree-Green M, Xie D, Rahat H, Garcia-Reyes Y, Bergman BC, Scherzinger A, Diniz Behn C, Chan CL, Kelsey MM, Pyle L, Nadeau KJ. Oral glucose tolerance test glucose peak time is most predictive of prediabetes and hepatic steatosis in obese girls. J Endocr Soc 2018;2:547-562.

12. Kim JY, Tfayli H, Bacha F, Lee SJ, Michaliszyn SF, Yousuf S, Gebara N, Arslanian $\mathrm{S}$. $\beta$-cell function, incretin response, and insulin sensitivity of glucose and fat metabolism in obese youth: Relationship to OGTT . time - to - glucose - peak. Pediatr Diabetes 2019;21:18-27. Epub 2019 Nov 14

13. Kanauchi M, Kimura K, Kanauchi K, Saito Y. Beta-cell function and insulin sensitivity contribute to the shape of plasma glucose curve during an oral glucose tolerance test in non-diabetic individuals. Int J Clin Pract 2005;59:427-432.

14. Abdul-Ghani MA, Lyssenko V, Tuomi T, Defronzo RA, Groop L. The shape of plasma glucose concentration curve during OGTT predicts future risk of type 2 diabetes. Diabetes Metab Res Rev 2010;26:280286.

15. Manco M, Nolfe G, Pataky Z, Monti L, Porcellati F, Gabriel R, Mitrakou A, Mingrone G. Shape of the OGTT glucose curve and risk of impaired glucose metabolism in the EGIR-RISC cohort. Metabolism 2017;70:4250. Epub 2017 Feb 14

16. Frøslie KF, Røislien J, Qvigstad E, Godang K, Bollerslev J, Voldner N, Henriksen T, Veierød MB. Shape information from glucose curves: Functional data analysis compared with traditional summary measures. BMC Med Res Methodol 2013;13:6.

17. Bervoets L, Mewis A, Massa G. The shape of the plasma glucose curve during an oral glucose tolerance test as an indicator of beta cell function and insulin sensitivity in end-pubertal obese girls. Horm Metab Res 2015;47:445-451. Epub 2014 Dec 15

18. Kim JY, Coletta DK, Mandarino LJ, Shaibi GQ. Glucose response curve and type 2 diabetes risk in Latino adolescents. Diabetes Care 2012;35:1925-1930. Epub 2012 Jun 29

19. Kim JY, Michaliszyn SF, Nasr A, Lee S, Tfayli H, Hannon T, Hughan KS, Bacha F, Arslanian S. The shape of the glucose response curve during an oral glucose tolerance test heralds biomarkers of type 2 diabetes risk in obese youth. Diabetes Care 2016;39:1431-1439. Epub 2016 Jun 12

20. Ismail HM, Xu P, Libman IM, Becker DJ, Marks JB, Skyler JS, Palmer JP, Sosenko JM; Type 1 Diabetes TrialNet Study Group. The shape of the glucose concentration curve during an oral glucose tolerance test predicts risk for type 1 diabetes. Diabetologia 2018;61:84-92. Epub 2017 Sep 27

21. Kuczmarski RJ, Ogden CL, Guo SS, Grummer-Strawn LM, Flegal KM, Mei Z, Wei R, Curtin LR, Roche AF, Johnson CLL. 2000 CDC Growth Charts for the United States: methods and development. Vital Health Stat 11 2000;246:1-190.

22. Kelly AS, Barlow SE, Rao G, Inge TH, Hayman LL, Steinberger J, Urbina EM, Ewing LJ, Daniels SR; American Heart Association Atherosclerosis, Hypertension, and Obesity in the Young Committee of the Council on Cardiovascular Disease in the Young, Council on Nutrition, Physical Activity and Metabolism, and Council on Clinical Cardiology. Severe obesity in children and adolescents: identification, associated health risks, and treatment approaches: a scientific statement from the American Heart Association. Circulation 2013;128:1689-1712. Epub 2013 Sep 9

23. Tanner JM. Growth and maturation during adolescence. Nutr Rev 1981;39:43-55. 
24. Tschritter O, Fritsche A, Shirkavand F, Machicao F, Haring H, Strumvoll $M$. Assessing the shape of the glucose curve during an oral glucose tolerance test. Diabetes Care 2003;26:1026-1033.

25. Matsuda M, DeFronzo RA. Insulin sensitivity indices obtained from oral glucose tolerance testing: comparison with the euglycemic insulin clamp. Diabetes Care 1999;22:1462-1470.

26. Phillips DI, Clark PM, Hales CN, Osmond C. Understanding oral glucose tolerance: comparison of glucose or insulin measurements during the oral glucose tolerance test with specific measurements of insulin resistance and insulin secretion. Diabet Med 1994;11:286-292.

27. Sjaarda LG, Bacha F, Lee S, Tfayli H, Andreatta E, Arslanian S. Oral disposition index in obese youth from normal to prediabetes to diabetes: relationship to clamp disposition index. J Pediatr 2012;161:51 57. Epub 2012 Feb 9

28. Wickham EP, Stern M, Evans RK, Bryan DL, Moskowitz WB, Clore JN, Laver JH. Prevalence of the metabolic syndrome among obese adolescents enrolled in a multidisciplinary weight management program: clinical correlates and response to treatment. Metab Syndr Relat Disord 2009;7:179-186.

29. Levy-Marchal C, Arslanian S, Cutfield W, Sinaiko A, Druet C, Marcovecchio ML, Chiarelli F; ESPE-LWPES-ISPAD-APPES-APEG-SLEPJSPE; Insulin Resistance in Children Consensus Conference Group. Insulin resistance in children: consensus, perspective, and future directions. J Clin Endocrinol Metab 2010;95:5189-5198. Epub 2010 Sep 8
30. Chung JO, Cho DH, Chung DJ, Chung MY. Associations among body mass index, insulin resistance, and pancreatic B-cell function in Korean patients with new-onset type 2 diabetes. Korean J Intern Med 2012;27:66-71. Epub 2012 Feb 28

31. Shah SS, Ramirez CE, Powers AC, Yu C, Shibao CA, Luther JM. Hyperglycemic clamp-derived disposition index is negatively associated with metabolic syndrome severity in obese subjects. Metabolism 2016;65:835-842. Epub 2016 Feb 26

32. Abdul-Ghani MA, Jenkinson CP, Richardson DK, Tripathy D, DeFronzo RA. Insulin secretion and action in subjects with impaired fasting glucose and impaired glucose tolerance: results from the Veterans Administration Genetic Epidemiology Study. Diabetes 2006;55:14301435.

33. Nolfe G, Spreghini MR, RW Sforza, Morino G, Manco M. Beyond the morphology of the glucose curve following an oral glucose tolerance test in obese youth. Eur J Endocrinol 2012;166:107-114. Epub 2011 Oct 18

34. Hulman A, Witte DR, Vistisen D, Balkau B, Dekker JM, Herder C, Hatunic M, Konrad T, Færch K, Manco M. Pathophysiological characteristics underlying different glucose response curves: a latent class trajectory analysis from the prospective EGIR-RISC study. Diabetes Care 2018;41:1740-1748. Epub 2018 May 31 